$<100 \mathrm{mg} /$ ) and lamotrigine $13.6 \mathrm{mg} /$ (normal range $<4 \mathrm{mg} /$ ).

After discontinuation of lamotrigine she became more communicative with clear improvement in cognition (MMSE 16/30) and a steady gait. Following two seizures she was recommenced on lamotrigine at $25 \mathrm{mg}$ b.d. Repeat serum level was $3.3 \mathrm{mg} / 1$. At six-month follow-up she remained seizure-free with a stable mental state.

This is a case of lamotrigine toxicity in a woman with known dementia presenting with gradual cognitive deterioration. Her increasing cognitive impairment could easily have been mistaken for the progression of her underlying dementing illness.

Valproate is known to inhibit the hepatic enzymes, notably causing a marked increase in the serum level of lamotrigine (British National Formulary, 1996, no. 32). In this case, however, the patient had been stabilised on this combination for the past two years without a change in dose. The mechanism of the raised serum lamotrigine levels remains unclear. When assessing a patient with a deterioration in cognitive function it is important to investigate for potentially treatable causes. Lamotrigine toxicity should be considered in all patients taking lamotrigine, in particular if taken in combination with valproate.

Buchanan, N. (1995) Lamotrigine: clinical experience in 93 patients with epilepsy. Acto Neurologica Scondinovica, 92, 28-32.

Folstein, M. F., Folstein, S. E. \& Mcturch, P. R. (1975) MiniMental State: A practical method for grading the cognitive state of patients for the clinician. Journol of Psychiatric Research, 12, 189-198.

W. P. Bouman, G. Pinner, H. Johnson

Department of Health Care of the Elderly, University Hospital QMC, Nottingham NG7 2UH

\section{Paroxetine discontinuation syndrome in association with sertindole therapy}

Sir: Sertindole is a novel atypical antipsychotic of great promise. We report a case in which we believe that sertindole therapy significantly worsened the symptoms of paroxetine discontinuation.

$D$. is a physically healthy 30 -year-old man who had a diagnosis of paranoid psychosis and unipolar depression. Following review, his depot neuroleptic medication was stopped and he was commenced on sertindole, the dose titrated as recommended to $20 \mathrm{mg}$ daily, and then paroxetine was stopped. He continued to complain of fatigue, poor motivation and somnolence. Severe withdrawal problems were not anticipated as he had previously stopped paroxetine completely with no ill effects. Within five days he became sleepless, sweaty, agitated and nauseous. There was no evidence of recurrent depressive or psychotic symptoms, and a diagnosis of 'serotoninergic syndrome' secondary to paroxetine withdrawal was made. Within two weeks he had returned to his pre-withdrawal state.

The severity of his reaction prompted us to investigate the interaction between paroxetine and sertindole further. Paroxetine increases serotonin availability by action on the neuronal membrane. It has been reported to down-regulate $5-\mathrm{HT}_{2}$ receptors on chronic admission. Sertindole antagonises 5 $\mathrm{HT}_{2}$ receptors, an effect enhanced by paroxetine-induced inhibition of sertindole metabolism. On stopping paroxetine, the cessation of these additive effects would leave insufficient serotonin to produce adequate stimulation for the subsensitive receptors. Neither we nor the manufacturers of sertindole (Lundbeck Ltd) have located previous reports of this phenomenon.

We note the possible increased risk of a serotoninergic withdrawal syndrome with paroxetine in patients being treated with sertindole, and recommend that paroxetine either be withdrawn before the commencement of sertindole, or with caution thereafter. The new atypical antipsychotic olanzapine is metabolised by the cytochrome $\mathrm{p} 450$ pathway and may also interact with paroxetine in this way.

\section{Walker-Kinnear, S. McNaughton}

Herdmanflat Hospital, Aberlady Road, Haddington, East Lothian EH4I 3BU

\section{Schizophrenia in Trinidad}

Sir: I was pleased to read the study by Bhugra et al (1996) about the incidence of schizophrenia in Trinidad as few data have been published about the epidemiology of psychiatric illness in the Caribbean. Comment was made on the lower rate compared with the African-Caribbean population in London.

However, Trinidad is different to the other Caribbean islands in that the population is only $43 \%$ African-Caribbean, with $40 \%$ of Indian descent, $14 \%$ mixed, $3 \%$ Chinese, $1 \%$ White and $1 \%$ other (Central Intelligence
Agency, 1995). I note the "total population of the relevant age-groups in the two catchment areas was 214048 ", and wonder how many of those were not African-Caribbean. The capital, Port of Spain (one of the catchment areas), is certainly not populated solely by African-Caribbeans. Similarly, being nonAfrican-Caribbean was not listed as an exclusion criterion, and the 56 patients reported were not explicitly identified as such.

From the information provided by the authors, the rate reported appears to be the incidence of schizophrenia in a multi-racial population, and comparison with AfricanCaribbean rates in the UK should perhaps be made with this caveat. Data from other Caribbean islands with more homogeneous populations may be more robust in such comparisons.

Bhugra, D. Hilwig, M., Hosseln, B., et al (1996) Firstcontact incidence rates of schizophrenia in Trinidad and oneyear follow-up. British journal of Psychiatry, 169. 587-592.

Central Intelligence Arency (1995) The World Foctbook 1995. Washington, DC: CIA.

D. A. Ratan Brandon Mental Health Unit, Leicester General Hospital, Gwendolen Road, Leicester LE5 4PW

Authors' reply: We read Dr Ratan's comments on our paper with interest. We acknowledge the diversity of the population within the descriptive term Afro-Caribbean. However, as the term African-Caribbean is used in the UK to include people who originate from a number of Caribbean territories, in the same way that White is used to include English, Irish, Welsh, Scottish and other groups, we decided to conform to the Office of Population Censuses and Surveys categories of ascription of ethnicity. We acknowledge that there are problems with such an approach, but until a different, more satisfactory classificatory system is devised this is what we have to work with. We recognise that the population in Trinidad is ethnically heterogeneous as is the White population in the UK. Because of the conventions we adopted we did not ascertain Trinidadian patients' self-ascribed ethnicity at the point of contact, hence we are unable to present incidence rates in various ethnic groups in Trinidad.

D. Bhugra, J. Leff, R. Mallett MRC Social, Genetic and Developmental Psychiatry Research Centre, Institute of Psychiatry, De Crespigny Park. London SE5 8AF 